\title{
EM DEFESA DO ESPAÇO LÍRICO
}

\author{
FERNANDO PAIXÃO
}

\section{RESUMO}

Desenvolve-se aqui uma reflexão sobre o poema em prosa no contexto do mundo contemporâneo. Examinando textos de quatro escritores representativos do gênero - o inglês John Berger, o francês Yves Bonnefoy, o norte-americano Tom Whalen e o alemão Heiner Müller —, o autor busca delinear os principais traços constitutivos dessa forma de expressão literária, que em sua diversidade de realizações se pautaria, de um modo geral, pela manifestação poética de uma extrema inquietude em relação à realidade vivida e por uma aguda autoconsciência da linguagem.

PALAVRAS-CHAVE: poema em prosa; literatura mundial contemporânea; lírica; linguagem.

\section{SUMMARY}

The essay presents a reflection on the prose poem in the contemporary world's context. Examining texts by four writers which are representative of this genre - the English John Berger, the French Yves Bonnefoy, the North American Tom Whalen and the German Heiner Müller -, the author seeks to outline the main constitutive traits of this literary expression's form, which in its diversity characterizes itself, in general, by the poetic expression of a extreme restlessness toward the experienced reality and by an acute self-consciousness of the language.

KEYWORDS: prose poem; contemporary world literature; poetry, language.

[1] Benn, Gottfried. "Problemas de la lírica". In: Vários autores. El poeta y su trabajo. Puebla (México): Editorial Universidad Autónoma de Puebla, 1985. Uma análise acurada sobre a trajetória do autor e suas idéias encontrase em Dierick, Augustinus P. Gottfried Benn and his critics: major interpretations 1912-1992. Columbia: Camden House, 1992.
O poeta alemão Gottfried Benn (1886-1956) produziu uma obra de caráter polêmico e, por ter se aproximado do regime nazista em certo período da vida, veio a sofrer forte discriminação. Felizmente, hoje há uma retomada na avaliação das suas idéias. Autor afinado com o ideário expressionista e corajoso nos posicionamentos estéticos, seus ensaios têm o mérito de colocar questões importantes para o entendimento do papel da literatura no contexto contemporâneo.A síntese de seu pensamento está expressa no texto "Problema da lírica", escrito por ocasião da entrega do Prêmio Büchner em 1951, no qual apresenta uma contundente avaliação da situação da poética em meados do século XX - diagnóstico que em boa parte ainda atinge os ventos da atmosfera que respiramos no presente ${ }^{1}$. 
Ao contrapor-se à idéia de que a poesia seria tão-somente a produção de poemas, ancorado sobretudo no uso do verso livre e no contraste de metáforas, Benn contesta uma fórmula comum e banalizada do que seja a poesia - a repetição de um hábito. Ele exige da lírica que proporcione de fato um "estado de ânimo" capturado por meio de palavras e imagens. E para que isso ocorra não basta ao poeta estar dotado de sentimentos. $\mathrm{O}$ importante será criar um modo particular de dizê-los, capaz de transmitir determinado contexto emocional. Segundo Benn, "por um lado há o elemento emotivo, o estado de ânimo, o elemento temático-melódico, e por outro o produto artístico. A nova poesia, a lírica, é um produto artístico. Com isso ganha a imagem de consciência, de controle crítico" ${ }^{2}$.

Conforme o raciocínio, a poética moderna estaria então estreitamente associada - mais ainda, submetida - a uma esfera racional predominante no que se refere à escrita literária. Para não se deixar seduzir pelo sentimentalismo barato ou pelas imagens déjà vues relacionadas aos temas correntes, cumpre ao escritor manter um estado de alerta em relação ao seu ofício. Por isso os poetas tanto se esforçam em enunciar uma filosofia da composição em paralelo ao movimento da criação. De acordo com Gottfried Benn, tal fato se deve a uma forte característica da poesia moderna: a "artisticidade". Esse conceito foi por ele definido como:

uma tentativa da arte, em meio à decadência geral dos conteúdos, de viver-se a simesma como conteúdoe, sobre essa experiência, de formar um novoestilo; é a tentativa, contra o niilismo geral dos valores, de instaurar uma nova transcendência: a transcendência do poder criador?.

Desse modo, o ato criador se apega a uma espécie de virtuosismo em torno dos recursos de expressão, como forma de se contrapor ao meio social. Ao afirmar uma atitude, o poeta investe na opção de ser um espírito maudit. E para chegar a tanto cabe negar até mesmo as categorias positivas de "realidade" e "conteúdo", substituindo-as por uma arte da qual ele deve se tornar um artífice consciente.

A partir da química interna do escritor surge então uma nova sensibilidade associada à lírica, ela mesma questionando os meios elimites da expressão. Identificado com essa perspectiva, o poeta anseia por realizar uma criação que seja capaz de transmitir o seu estado de vivência, dando voz a uma subjetividade que se contraponha às condições da existência ordinária. Por conseguinte, o sujeito poético se torna um ponto de fuga para o qual convergem as imagens de mal-estar no mundo.

Atualizando o sentimento niilista de Nietzsche - que muito o influenciou -, Gottfried Benn concorda com o autor de Ecce uomo ao defender um caminho que leva do conteúdo à expressão, vale dizer,
[2] Benn, op. cit., p. 66. Tradução de Fernando Paixão.

[3] Ibidem, pp. 69-70. 
que promove o apagamento da substância em favor da forma. O que ambos apregoam, no final das contas, é uma linguagem inquieta consigo mesma e que desse modo seja capaz de gerar uma experiência poética original.

Esse seria, em síntese, o desafio central da poesia moderna - e com maior ênfase ainda no caso deste gênero recentee indeterminado: o poema em prosa.A pensar sob a ótica de Benn, écomo seesse tipo de escrita cumprisse ainda hoje, de maneira mais fecunda que a escritura em versos, o papel de levar a poesia a "viver-se como conteúdo". Por se tratar de uma composição fundada no contraponto e na ambigüidade, cabe ao autor explorar os limites dessa tensão até produzir o efeito estético desejado.

É freqüente, pois, depararmo-nos com uma escrita que processa as imagens em estado de alta voltagem e mobiliza uma percepção de elementos desconcertantes, ora adotando um viés de racionalidade, ora levando a imaginação a explorar um livre campo de associações. De um modo ou de outro, sobressai o gosto por uma atmosfera de cunho dramático.

O drama em questão (muitas vezes atravessado de ironia) aparece expresso não apenas no plano das imagens, mas igualmente no (auto)questionamento do poder criador das palavras. Por isso mesmo, a metalinguagem costuma ser um viés recorrente nesse tipo de escrita. É como se boa parte dos poemas em prosa quisesse partilhar com o leitor uma inquietude que também supõe a angústia da expressão.

A dispersão apresentada no fluxo das imagens converge paradoxalmente para oferecer um flagrante (em forma escrita) da percepção subjetiva. Funda-se então um sujeito por detrás das frases, muitas vezes assumindo um tom de monólogo. Esse viés leva o "eu" manifesto a desempenhar um papel de elemento unificador, ponto de convergência para a dispersão imaginativa que contagia o poema.

São raros os textos com esse poder sugestivo de nos fazer perceber novos nexos. Quando deparamos com algum, dotado de força e originalidade, acontece um fato poético único e singular. Um clarão toma a página e ilumina a leitura. Somos conduzidos a um pensamento em estado de atenção ao longo de frases que propõem um lance furtivo (e dramático) envolvendo imagens e sons.

Poemas raros, sem dúvida. Mas que recompensam o esforço de procurá-los em meio a tantos livros dispostos na prateleira. Necessário folhear páginas e páginas, ler inúmeros poemas, descartar a maior parte e deixar os duvidosos no limbo para então selecionar uns poucos que possam aqui servir de exemplo. Em meio a uma farta e diversificada produção de livros desponta a tarefa de escolher peças em sintonia com as questões levantadas. 
Alguns textos podem ser encontrados na obra de autores que se dedicam exclusivamente à poesia, e outros na produção daqueles que escrevem romances, ensaios ou peças, mas volta e meia escolhem o poema em prosa como o formato mais adequado à inspiração. Em comum, apresentam um espírito alimentado de inconformidade e aproximam-se da experimentação poética, num claro esforço de contraste com a vida contemporânea e seus artifícios de linguagem.

Comecemos então por um texto que terá sua autoria revelada mais adiante. Antes, interessa-nos o contato com a sensorialidade das frases que seguem:

Aquilo que me reconcilia coma minha própria morte é, mais do que outra coisa qualquer, a imagem de um lugar: um lugar onde os teus ossos e os meus fiquem sepultados, atirados para ali, nus, juntos. Disseminados, numa confusão desordenada. Uma das tuas costelas está apoiada contra o meu crânio. Um metacarpo da minha mão esquerda repousa dentro da tua bacia. (Contra as minhas costelas quebradas, o teu seio, parecido com uma flor). As centenas de ossos dos nossos pés estão dispersas como areia. É estranho que esta imagem da nossa proximidade, apenas ligada por fosfato de cálcio, possa produzir um sentimento de paz tão grande. Mas é isso, precisamente, o que acontece. Contigo eu posso imaginar um lugaronde me seja suficiente nãoser mais do que fosfato de cálcio 4 .

Misto de horror e de júbilo, o poema sugere uma reunião de sentimentos opostos correndo por sobre um fio de navalha. Sem medo de encarar a própria morte, nem a visão minimalista dos ossos a que se vê reduzido, o sujeito lírico reencontra nesse espaço a presença da amada. Já de partida misturam-se as substâncias da decomposição e do afeto, antípodas e vizinhas naquele lugar extremo em que se projeta o imaginário.

A pequena reflexão acontece com naturalidade, como se fosse uma anotação fortuita, mas de olho fixo na fatalidade. A visão do horror chega a ser envolvida pelo poder da vontade e do sentimento amoroso, levando o texto a ganhar um viés de educação sentimental: "Contigo eu posso imaginar um lugar onde me seja suficiente não ser mais do que fosfato de cálcio". Da confusão desordenada dos corpos, concluise pela percepção de um outro plano capaz de contrastar com o ambiente negativo da morte.

Contribui para isso o fato de que o texto se enuncia a partir de uma ótica de reconciliação expressa desde a primeira frase. Assim, a imagem original da sepultura surge invocada na qualidade de algo pacificado, absorvido pela experiência do sujeito. Apostando na instigante dualidade que pendula entre a imagem degradada e o

\author{
[4] Revista Construções Portuárias \\ (Lisboa), n 1, 2002, p. 20. Tradução \\ de Antonio Cabrita.
}


pensamento luminoso, entre a decomposição e o resgate amoroso, 0 poema ganha expressividade porque assume uma perspectiva sentimental no delinear das imagens. A cada frase aumenta o distanciamento em relação ao contexto degradado. A matéria corpórea se revela numa face cruel, mas acompanhada do avesso simbólico: "o teu seio, parecido com uma flor". Imagens sobrepostas e antitéticas, mas que mantêm força justamente pelo fato de permanecerem complementares até o desfecho, quando os amantes restauram o amor entre resíduos de cálcio.

Curiosamente, o gosto final da leitura é marcado por uma atmosfera de elegia, reforçada na última frase. Faces de uma só moeda, o amor e a morte, a paz e o tormento encontram-se fundidos num espaço imaginário único, tornado possível por meio da palavra poética. Com efeito, o texto sustenta uma dimensão simbólica que se sobrepõe à realidade, capaz de sugerir correspondências para além do plano imediato.

Seu autor é o inglês John Berger, dotado de múltiplos talentos literários. Dedicado tanto ao romance (ganhador do Booker Prize de 1972) como à poesia, ele também escreve para teatro e tem prestigiosa reputação como crítico de arte. Coerente com sua visão de mundo, trocou a Inglaterra pela França e atualmente mora na região da Provença, deliberadamente recolhido para escrever. Sua biografia remonta a uma juventude rebelde, quando abandonou o curso de Oxford aos dezesseis anos, o que cedo o levou a iniciar uma vida profissional como pintor e professor de desenho. Marcado pelo drama da Segunda Guerra e pela influência das leituras marxistas, inspiradas pelos pais, seu pensamento logo enveredou por um viés crítico, exigente e mal-humorado em relação à cultura contemporânea.

As várias facetas, contudo, revelam uma forte coerência interna quanto aos valores estéticos. Ao mesmo tempo em que evoca o pensamento poético em seus escritos sobre arte, Berger é capaz de levar a poesia a um estado de observação próximo do pensamento reflexivo. Pertence a um grupo diferenciado de escritores que exercem sua arte inspirando-se numa perspectiva de ativismo político.

O poema acima faz parte de um de seus livros heterodoxos dotado de estranho título: And our faces, my heart, brief as photos (1984) -, em que se permitiu a liberdade de reunir um conjunto de textos variados, inquietos e de proposta totalmente indefinida quanto ao gênero. Ora apresenta uma reflexão estética em formulação densa e teórica, ora versos em poucas linhas que buscam um diálogo interno com o trecho anterior. Alguns textos, de caráter mais lírico que conceitual, podem ser considerados poemas em prosa.

Num dos fragmentos desse livro, Berger tece uma reflexão teórica que claramente dialoga com a voz poética e sugere uma possível chave para o seu entendimento. Diz ele: 
Ospoemas, mesmo quando são narrativos, não se parecem nada com histórias. Todas as históriassão acerca das batalhas, de uma espécie ou de outra, e sempre acabam com vencedores e vencidos. Tudo se orienta na direção de determinado fim, para então se saberqual éo desfecho.

E em seguida desenvolve uma conclusão que bem poderia servir para caracterizar os seus escritos poéticos:

Os poemas, que não lidam com desfechos de nenhuma ordem, atravessamos campos de batalha, cuidam dosferidos e ouvem os monólogos delirantes de triunfantes e derrotados. Trazem consigo uma espécie de paz. Não por qualquer virtude anestesiante ou fácil consolação, mas por conterem o reconhecimento e a promessa de que as experiências não podem desaparecer como se nunca tivessem existidos.

Como se vê, voltam à tona argumentos afins aos de Gottfried Benn, que certamente concordaria em associar a lírica a uma perspectiva de "monólogos triunfantes e derrotados". À beira dos impasses, o imaginário poético cumpre a função de flagrar a subjetividade. Provavelmentevem daí a tendência desse tipo de texto a aderir ao tom meditativo, como que fechado em concha.

Efeito semelhante pode ser observado quando o discurso lírico apresenta uma face menos vinculada à percepção do sujeito para voltar-se ao próprio umbigo, vale dizer, para perceber as nuanças do meio de que dispõe: a linguagem. Descobriremos, então, poemas que tratam de si mesmos ou miram-se como que num rio de palavras, a duvidar delas ou a questioná-las - metalinguagem que aparece registrada em pele de poema em prosa.

Nesse quesito, o poeta francês Yves Bonnefoy pode ser lembrado como uma voz significativa da atualidade. Não apenas porque aprecia escrever utilizando-se dessa maneira prosódica (presente em vários de seus livros), mas sobretudo porque é poeta de fina sensibilidade, consciente de que a linguagem dispõe armadilhas a que se deve estar atento. A força de sua poética, aliás, deriva de certa desconfiança quanto à qualidade representativa das palavras.

Não por acaso, durante a juventude, chegou a manter contato com o grupo surrealista de André Breton, mas logo se distanciou dele por discordar dos seus princípios estéticos. Foi estudar matemática e depois filosofia, o que muito veio a influenciar-lhe o modo de entender a arte. Sua estréia poética ocorreu em 1947, com um opúsculo de poemas em prosa cujo título - nada menos que Anti-Platão - anunciava uma clara opção de horizontes. Desde então sua obra reúne mais de quarenta títulos, diversificados entre a poesia, o ensaio literário e a crítica de arte.
[5] Berger, John. And our faces, my hearth, brief as photos. Nova York:Vintage, 1991, pp. 21-22. Tradução de Fernando Paixão. 
[6] Bonnefoy,Yves.Obrapoética.Trad. de Mário Laranjeira. São Paulo: Iluminuras, 1998, p.19.
Inspirado nos exemplos de Baudelaire e Rimbaud (seus autores preferidos), colocou-se em franca defesa de uma literatura rigorosa e manteve sob suspeita a linguagem corrente, saturada de signos e imagens. Mais que uma escrita, a poesia deve implicar uma atitude renovadora da linguagem e do mundo. Para tanto, defende uma poética sem ornamentação e distante dos maneirismos, como expressou claramente no prefácio que escreveu especialmente para a edição brasileira de seus poemas:

A linguagem nos dá o mundo, éverdade, devemos-lhe os objetos com que vivemos e muitos aspectos das coisas, que ela nos revela. Mas as palavras pelas quais esses objetos, esses aspectos e a idéia que deles temos tomam forma, a ponto de logo ocupar todo o campo de nossa experiência;essas palavras são, cada uma, portadoras de representações simplesmente mentais, definitivamente abstratas, que nada sabem do instante que se tem a viver, nada do lugar em que isso se dá, em suma, do acaso pelo qual nós somos, nada do tempo em suma, nada do tempo queéa relação maisintima a nós mesmos, nada daquilo a que chamarei a nossa finitude ${ }^{6}$.

Bonnefoy sugere, portanto, uma vigilante atenção para com a linguagem, de modo a não se deixar cair em discursos vazios ou alienados quando tratam da experiência vivida no instante. "A poesia é essa luta contra a língua", sentencia ele, justificando a procura por uma unidade existencial que transcenda a mera expressão literária. Coerentemente com tal visão, são recorrentes em sua poética certos temas relacionados à valorização do tempo presente e do vrailieu ("verdadeiro lugar").

$\mathrm{Na}$ verdade, a visão de Bonnefoy implica uma valoração ética em relação ao ato da escrita, no sentido de que este se coloca derrotado de antemão com o intuito de atingir o cerne dos momentos vividos. "A linguagem não é o verbo", sentencia ele, e complementa: "assim deformada, assim transformada que possa ser em outra sintaxe, ela não será mais que uma metáfora da sintaxe impossível, não significando mais que o exílio". Cabe ao poeta revelar o exílio experimentado no âmbito da própria linguagem, em contraponto a uma realidade objetiva que atinge os sentidos.

Exilado na expressão, o autor procura voltar-se para o mundo real e precário a fim de experimentar com ele uma outra espécie de contato - mas como expressá-lo em palavras? Incerta, a linguagem coloca-se à prova de si mesma, levando os signos ao rodopio por meio de imagens afirmativas e contagiantes. Esta seria, aliás, uma possível suma para a sua poética, especialmente sensível ao esvaziamento do poder sugestivo das palavras.

Como antídoto a essa inevitável decadência, Bonnefoy propõe a volta ao presente e ao imediato: 
Coisas todas daqui, terra do vime, do vestido, da pedra, quer dizer:terra da água sobre os vimes e as pedras, terra das vestes manchadas. Esse riso coberto de sangue, eu vo-lo digo, traficantes de eterno, rostos simétricos, ausência de olhar, pesa mais na cabeça do homem do que as perfeitas Idéias, que só sabem desbotarsobre sua boca7.

É o que afirma a segunda e última estrofe de seu primeiro poema antiplatônico - portanto, a primeira página de sua obra, desde a qual optou por valorizar a dubiedade do real e rejeitar o abrigo das "perfeitas idéias" que possam estar disponíveis. Em direção oposta ao puro encantamento com a linguagem, esse poeta deseja alcançar a aquisição de um "saber negativo" 8 , atento à passagem do tempo e das coisas, aberto a se emocionar com elas e buscar um registro verbal correspondente. Para tanto é preciso um cauteloso distanciamento quanto aos artifícios da linguagem. Herdamos um mundo de palavras poluídas em seu significado e uso, e a isso devemos prestar muita atenção, como sugere Bonnefoy no poema transcrito a seguir.

\section{Do significante}

A primeira palavra foi "a nuvem", a segunda "a nuvem" também, a terceira, a quarta, etc. foi "a nuvem" ou "o céu" ou "o ar",já não sabemos mais.

Mas já a sétima se rasgou, se desfez, não se distinguia mais do rasgo, do apagamento de outras mais baixas, de outras ao infinito, de outras cinza, de outras quase pó, branco, que remexemos, em vão, dentro do grande saco de pano grosseiro, o que restou da linguagem 9 .

Texto curto e de imagens fortes, realça a adversidade enfrentada no campo das palavras; reproduzidas à exaustão, transformaram-se num pó branco, remexido no "saco de pano grosseiro, o que restou da linguagem". Por conta da repetição e da desatenção freqüentes, as palavras se gastam e se afastam do sentido de origem. Entendidas como puro instrumento, perdem o frescor do significado para se tornar algo opaco, próximo das cinzas - derradeiro grau de suas propriedades.

$O$ poema sugere ainda que as palavras instauram um princípio de recusa. A repetição do termo "nuvem" obscurece a referência e chega a comprometer o seu próprio sentido, confundindo as coisas: "foi 'a nuvem' ou 'o céu' ou 'o ar', já não sabemos mais". Desorientado, o sujeito já não dispõe do léxico com liberdade; ao contrário, tem como ponto de partida precaver-se das armadilhas da linguagem.

Por vezes, porém, o viés crítico (e metalingüístico) dos poetas resulta num questionamento do próprio gênero. $\mathrm{O}$ texto transcrito a seguir faz parte desse imaginário e foi escrito por Tom Whalen, autor norte-americano que pratica o gênero desde 1976, o que lhe faculta referir-se ao assunto em termos tão diretos.
[7] Ibidem, p. 23 .

[8] Idem. "Lacte et le lieu de la poè-
sie". In: L'improbable. Paris: Mercure de France, 1980 , p. 126.
[9] Idem. Rue traversière et autres récits en rêve. Paris: Gallimard, 1992, p. 76. Tradução de Fernando Paixão. 
[10] In: Lehman, David. Great american prose poems: from Poe to present. Nova York: Scribner Poetry, 2003, p. 205. Tradução de Fernando Paixão.
Porque eu odeio poema em prosa

Um homem raivoso entrou na cozinha onde sua mulher estava ocupada com ojantare explodiu.

Minha mãe contava-me essa história todos os dias de sua vida, até que um dia ela explodiu.

Mas isso não é uma história, ela sempre lembrava. É um poema em prosa.

Certo dia vi um homem dando um cachorro-quente ao seu cachorro. Ocachorro-quente parecia uma banana de dinamite.

Com freqüência qualquer sinal de poema em prosa me deixa doente.

Eu sou solteiro e moro sozinho numa pequena casa.

Durante meu tempo livre, vou cultivando um jardim noturno ${ }^{10}$.

As imagens aqui apresentadas evidentemente supõem um componente de ironia, responsável pelo atrito entre frases com significados tão distintos. $O$ proclamado ódio do autor a essa escrita, enredado em peculiaridades tão pessoais e cotidianas, acaba por ressaltar o seu contrário, tal é a paradoxal aproximação dos elementos. Ao misturar referências distintas de maneira tão seca e direta — pulando da mulher que explode para a auto-referência ao gênero e ao cachorro que come hot dog em forma de dinamite - o autor produz um tal giro de imagens que o texto acaba por configurar um efeito poético de anulação mútua de significados, o qual atinge até mesmo o título. Curioso: ao término da leitura, logo percebemos que ele significa o contrário daquilo que afirma. Artes e manhas da língua, pois.

Uma outra vertente que leva o poema em prosa a "viver-se como conteúdo" pode ser encontrada em textos que explicitamente buscam estabelecer um diálogo com nomes e valores da tradição, mas sob o compromisso de tornar contemporâneos os problemas colocados por obras de outros tempos e sociedades. Não se trata,é claro, da mera imitação de modelos do passado, e sim de uma recriação de seus temas e ícones a partir de referências atuais.

Um autor que conscientemente se volta para essa direção é o alemão Heiner Müller, falecido em 2005. Conhecido sobretudo por suas peças teatrais, ele na verdade se posicionou como um escritor-intelectual, dividido entre a crítica do socialismo fracassado de seu país de origem - a então Alemanha Oriental - e a recusa dos valores consumistas que encontrou nas democracias ocidentais. Como manter ativo um espírito de revolta que se opusesse a essas forças sociais tão perversas? Que valor teria a arte em sociedades tão controladoras quanto as atuais?

Movido pelo desejo de empreender uma escrita aliada da lucidez política, Müller conseguiu afastar-se dos maniqueísmos típicos de 
boa parte da estética inspirada nos valores marxistas do século XX. Iniciou carreira nos anos 1950 seguindo as proposições de Bertold Brecht, das quais veio a distanciar-se em busca de um estilo próprio. Alcançou a maturidade autoral na década seguinte com suas peças inspiradas em figuras da Antigüidade, tais como Hércules (1964), Édipo Rei (1966) e Prometeu (1967). Com esse ciclo de textos ele aprofundou a opção por uma arte de fundo ideológico, mas alimentada por um rico imaginário poético apoiado em frases cortantes, que dão curso a um pensamento crítico e reflexivo. Seu projeto estético continuou se radicalizando em obras posteriores, entre as quais Máquina-Hamlet (1979), A missão (1982), Quarteto (1982) e Germânia (1985).

Nas peças do autor, a trama e os episódios muitas vezes são apresentados sem continuidade, de modo nitidamente fragmentário, suscitando no espectador estranheza e consciência simultaneamente. Müller procurou atualizar o distanciamento crítico proposto por Brecht, mas à luz de uma abordagem mais complexa e dotada de uma poética distinta. Testemunha que foi das tragédias ocorridas na Segunda Guerra, desenvolveu uma visão de mundo cética e desesperançada. Misturando diferentes discursos em cena - do diálogo à preleção, da análise ao monólogo -, sua dramaturgia visa fundar um espaço de contínuo questionamento.

Tom igualmente incisivo vamos encontrar em seus poemas, incluindo aqueles por vezes escritos em prosa. Dentre esses textos destaca-se um em que Müller trava explícito diálogo com um famoso e belo trecho de Walter Benjamin quevale a pena relembrar. Trata-se de um fragmento escrito em 1940, ano em que Benjamin acabou por suicidar-se em meio aos horrores da guerra.

Comovido por um quadro de Paul Klee, o pensador da Escola de Frankfurt vê ali a figuração do anjo da história, no qual transparece o agudo desejo de "querer afastar-se de algo que ele encara fixamente". Premido entre forças contrárias, o anjo mostra-se tenso e atônito, com olhos e boca escancarados e as asas bem abertas:

Onde nós vemos uma cadeia de acontecimentos, ele vê uma catástrofe única, que acumula incansavelmente ruína sobre ruína e as dispersa aos nossos pés. Ele gostaria de deter-se para acordar os mortos e juntar os fragmentos. Mas uma tempestade sopra do paraíso e prende-se em suas asas com tanta força que ele não pode mais fechá-las. Essa tempestade o impele irresistivelmente para ofuturo, ao qual ele vira as costas, enquanto o amontoado de ruínas cresce até o céu. Essa tempestade éo que chamamos progresso ${ }^{11}$.

Ao empreender uma leitura livre e ousada do quadro de Klee, Ben-

[11] Benjamin, Walter. Obras escolhidas I: magia e técnica, arte e política. Trad. de Sérgio Paulo Rouanet. São Paulo: Brasiliense, 1989, p. 226. 
[12] In: Müller, Heiner. $O$ anjo do desespero. e abstrato como o de história. Envolto em bruma, o anjo vê-se dividido entre passado e futuro, contraste expresso na figura das ruínas crescentes e na imagem da tempestade que o arremessa, mas se mantém de costas para o futuro - às cegas, pode-se entender.

Esse texto faz parte de um conjunto de fragmentos dedicados a refletir "Sobre o conceito de história", e é de fato o mais poético de todos. Em meio a vários escritos conceituais acerca do tema, o filósofo recorre a um recorte inesperado e invoca uma imagem de forte conteúdo poético. Para além da fronteira entre as disciplinas, o texto bem pode ser considerado um poema em prosa.

Decerto ciente dessa qualidade, Heiner Müller escreveu uma nova versão para o anjo atormentado de Benjamin. Como que movido pela vontade de atualizar a imagem dessa criatura atarantada, o dramaturgo mobiliza os mesmos elementos evocados pelo filósofo em um ambiente diferente e em um outro jogo de forças. $\mathrm{O}$ anjo representado por Klee ganha assim uma nova aparição, denunciada já no título:

\section{Oanjo sem sorte}

Atrás dele o passado dá à costa, acumula entulho sobre as asas e os ombros, um barulho como de tambores enterrados, enquanto à sua frente se amontoa ofuturo, esmagando-lhe os olhos, fazendo explodir como estrelas os globos oculares, transformando a palavra em mordaça sonora, estrangulando-o com o seu sopro. Durante algum tempo vê-se ainda o seu bater de asas, ouvem-se naquele sussurrar as pedras a cair-lhe àfrente por cima atrás, tanto mais alto quanto maisfrenéticoé o escusado movimento, mais espaçadas quando ele abranda. Depoisfecha-se sobre ele o instante: no lugar onde está de pé, rapidamente atulhado, o anjo sem sorte encontra a paz, esperando pela História na petrificação do vôo do olhar do sopro. Até que novo ruído de portentoso bater de asas se propaga em ondas através da pedra e anuncia o seu vôo ${ }^{12}$.

Esse anjo difere do anterior sob vários aspectos, até o ponto de voltar-se para direção oposta: ele mira o futuro, enquanto o outro está condenado a enxergar as ruínas do passado. Concebido no final do século XX - resumindo portanto os horrores do período - o personagem de Müller encontra-se diante de uma paisagem ainda mais estonteante, dramática e multiforme, em fecundo contraste com a condição angelical, num descompasso que só cresce à medida que se acumulam as imagens.

É importante observar que o anjo do filósofo está condenado a permanecer de asas abertas, enquanto o "anjo sem sorte" debate-se por conta de oferecer resistência: "Durante algum tempo vê-se ainda o seu bater de asas, ouvem-se naquele sussurrar as pedras a cair-lhe à frente por cima atrás, tanto mais alto quanto mais frenético é o escusado 
movimento". Somados os elementos, resta uma impressão de grande sufoco e adversidade. Mas já no momento seguinte esse anjo acena com uma fresta, inexistente no antecessor. Fecha-se sobre ele o instante - diz o texto de Muller - como que forjando uma nova dimensão, queé acolhedora ao ser angelical elhe permite al cançar algum sentimento de paz, à espera dos ventos da história. Esta, por sua vez, mostra-se como a "petrificação do vôo do olhar do sopro" - enigmática expressão fundada na ação interna do contraponto.

No momento derradeiro, temos ainda a novidade do vôo anunciado. É dada ao anjo, tocado pela redenção do instante, a possibilidade de sair daquele lugar onde lhe coube pouca sorte. Alguns podem entender nessa imagem final a representação de uma saída para a liberdade, o rompimento do jugo pela força das asas; mas haverá quem prefira interpretar a frase no sentido figurado do exílio, vendo o anjo como que arremessado para fora da história. Dono do seu destino ou vítima da violência? Ação ou reação? Livre ou fugitivo? A qualidade do poema está em colocar essas questões em movimento reforçando-lhes a ambivalência simbólica, sem oferecer resposta definitiva. A rigor, a situação termina em suspenso, passível de muitas interpretações, e isso faz parte do encanto e da estranheza do texto. Müller consegue revelar uma paisagem ainda mais terrível do que as anteriores, mas com o desfecho aberto para o vôo. Saída para o poético, talvez.

Lidos em conjunto, esses poemas e autores servem para circunscrever um recorte em torno de uma produção poética singular, dotada de alta consciência estética. Rara poesia, portanto. Mas possível de se encontrar na voz de autores dessa linhagem, de natureza inclassificável, que gostam de experimentar diferentes maneiras de escrita e acreditam que isso ajuda a ampliar o campo poético da atualidade.

Por certo representam escolhas pessoais, discutíveis sob vários aspectos. Mas espera-se que os textos aqui apresentados elucidem o quanto a noção de artisticidade se mantém como uma chave importante (ainda que não a única) para o entendimento da poética que hoje se pratica. À entrada do século XXI, continua sendo vital e estimulante para o artista o distanciamento crítico em relação à sociedade em que vive e à linguagem de que se serve.

Tal afirmação é ainda mais verdadeira no que se refere ao poema em prosa. Seja pelos motivos arrolados no início deste ensaio, seja pelo argumento derradeiro de que essa escrita trabalha a imaginação poética a partir do grau zero - sem apoio de modelos prévios - o o fato é que cada texto deve se empenhar em criar os meios e modos compatíveis com o conteúdo poético que deseja expressar. 
Recebido para publicação

em 10 de setembro de 2007

NOVOS ESTUDOS

CEBRAP

80 , março 2008

pp. 205-217
Trata-se de uma escrita não raro inspirada no acidental, de modo que em muitos casos assume um tom de anotação, página de diário, meditação íntima ou algo assim. E com freqüência recorre ao tom reflexivo para ordenar as frases e as idéias. Propondo-se a constituir uma terceira margem entre as vertentes conhecidas, o poema tem de encontrar um lugar entre os extremos e se reinventar a cada ocorrência.

Posicionar-se em defesa do espaço lírico e desconfiar das palavras: eis os possíveis desafios que motivam escritores diversos a se manifestar nesse gênero híbrido e fecundo. Sobretudo quando se trata de registrar determinadas situações, percepções e imagens movidas por um estado de inquietude, compatível com a vertiginosa confusão de sentidos a que estamos expostos hoje.

Tanto prosa quanto poesia, reconhecemos nessa vertente literária uma vocação bifurcada. Escrita do desassossego.

FERNANDO PAIXÃO é editor e poeta. Autor de Poeira (Editora 34, 2001) e Narciso em sacrifício (Ateliê, 2003), entre outros livros. 